\title{
Subsurface ${ }^{18} \mathrm{O}$ exchange at low temperatures: The (GMWL) plot thickens
}

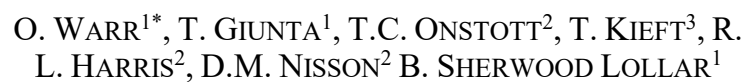

${ }^{1}$ Dept of Earth Sciences, Univ. of Toronto, Canada

*correspondence: oliver.warr@utoronto.ca

2 Dept of Geosciences, Princeton, USA

${ }^{3}$ Dept of Earth \& Environmental Science, NMT, USA

Reduced-gas-rich $\mathrm{Ca}-\mathrm{Na}-\mathrm{Cl}$ fluids hosted within fractures in crystalline Precambrian rocks occur globally, and have been studied extensively in the Fennoscandian and Canadian Shields and the Kaapval Craton in South Africa ${ }^{1-3}$. The $\delta^{18} \mathrm{O}$ and $\delta^{2} \mathrm{H}$ values for these fluids characteristically plot to the left/above of the Global Meteoric Water Line (GMWL), in contrast to other fluids that lie beneath the GMWL, e.g. sedimentary basin brines and hydrothermal fluids. Proposed mechanisms for these signature include isotopic exchange with a $\mathrm{H}_{2}$-rich gas, $\mathrm{H}_{2}$ formation from water, silicate hydration coupled with formation of secondary minerals, or isotope exchange with $\mathrm{O}$ and/or H-bearing minerals. To date, most analysis has focused on processes affecting both ${ }^{18} \mathrm{O}$ and ${ }^{2} \mathrm{H}$ values resulting in co-variation of data above the line ${ }^{1-3}$.

We have compiled a global isotopic dataset of crystalline fluids to evaluate these potential mechanism(s), including the role of meteoric-non-meteoric fluid mixing. From 2-3 km deep shield brine end-members identified at Kidd Creek Mine, Canada, we highlight the relatively little variation in the $\delta^{2} \mathrm{H}$, suggesting $\delta^{18} \mathrm{O}$ isotopic processes may play the primary role in these fluids plotting to the left of the GMWL. The co-variation in ${ }^{18} \mathrm{O}-{ }^{2} \mathrm{H}$ space previously noted in the literature may be more related to mixing. Modelling demonstrates these fluids are at low-temperature equilibrium with silicate-bearing minerals (e.g. quartz and calcite), a finding consistent with their estimated extremely long in situ mean residence times ${ }^{4}$. These findings suggest a common global source associated with initial high-temperature metamorphic/hydrothermal fluids. Subsequent low-volume water-rock reactions at low temperatures over long geologic time result in progressive $\delta^{18} \mathrm{O}$ fluid depletion as equilibrium is reached, with the exact value depending on initial hydrothermal fluid compositions, rates of isotopic exchange, water-to-rock ratios, and in-situ residence times. Recent meteoric water addition via natural/anthropogenic processes results in site-specific brine-GMWL mixing lines ${ }^{1-3}$.

${ }^{1}$ Sherwood Lollar et al. (1993) GCA 57, 5073-5085. ${ }^{2}$ Onstott et al (2006) Geomicrobiol. J. 23, 369-414. ${ }^{3}$ Clark I. D. \& Fritz P. (1997) CRC press. 328 pp. ${ }^{4}$ Holland et al. (2013) Nature 497, 357-360. 